\title{
The widespread hotel: New hotel model for business tourist
}

\author{
Filippo Monge ${ }^{1}$, Daniele Cattaneo ${ }^{2}$, Angela Scilla ${ }^{2}$ \\ ${ }^{1}$ Department of Economia e Statistica “Cognetti de Martis”, University of Turin, Turin, Italy \\ ${ }^{2}$ Department of Management, University of Turin, Turin, Italy
}

Email address:

filippo.monge@unito.it (F. Monge), daniele.cattaneo@unito.it (D. Cattaneo), angela.scilla@unito.it (A. Scilla)

\section{To cite this article:}

Filippo Monge, Daniele Cattaneo, Angela Scilla. The Widespread Hotel: New Hotel Model for Business Tourist. Journal of Investment and Management. Special Issue: Attractiveness and Governance of Tourist Destinations. Vol. 4, No. 1-1, 2015, pp. 69-76.

doi: 10.11648/j.jim.s.2015040101.19

\begin{abstract}
The territories are in competition among them for attract human, economic and financial resources. The attractiveness has become the target of recent urban policies. In fact, the constant appeals to events, be they even simple events or events lasting more days, or real places built for the occasion and adaptable to multiple uses, all linked to recreational activities, are a proof. In the tourism field this situation is particularly intense. The local areas can lose the competitive play against the great areas. They must think of diversification of their supply. Therefore, in the dynamic environment of business tourism, the requirements of customers about service quality and location landscape are getting harder than in the past. The widespread hotel model represents one of the possible solution to that needs and recently it is increasing its importance. The model is able to stimulate economic and social value development through the management of several critical success factors. The analysis of a case study "Hotel Chateau Le Cagnard" permits to underline the key factors of success of the widespread hotel for business tourism.
\end{abstract}

Keywords: Territorial Competitiveness, Widespread Hotel, Business Tourist

\section{Introduction}

Tourism is one of the sectors that has the ability to improve the competitiveness between the territories, to promote territorial innovation [1] and thus enhance the attractiveness of the destinations [2], [3].

This is most important in small tourist areas and especially in rural ones, where need to tools and initiatives to increase income and employment, through the enhancement of local resources [4].

Thanks the implementation of tourism policy, an area can get a set of benefits. It should, however, consider that tourism is a driver that can determine strong impact, even negative, on the land and on the local community [5], [6].

Therefore, it is essential to bear in mind the definition of services and activities that improve the tourism sector, the extent of the impacts that these determine in the development of the local area, to avoid that there is a crisis.

It is therefore necessary to combine the needs of local development with the preservation of culture and local specificities.

All this must also be reconciled with the needs of the leisure or business tourist. In fact, in the tourism industry, most of economic value is represented by experiences [7]. The tourism demand is experiencing, in fact, in recent years, a particular evolution process, which causes the increase of the degree of variety (always more marked segmentation processes) and variability in time and in space. The enterprises and tourism system, in fact, should guide their strategic and marketing choices to the differentiated and personalized solutions, respecting the criteria of economy and efficiency of management decisions. To supply experiences seems to be a way for makers to survive in the ever more competitive future [8].

The hotel model known as widespread hotel seems to offer an answer to all these problems. In fact it has a network of "local flavor" houses, uninhabited and pre-existing, that are able to operate as a hotel; a network of public and private entities that start a process of collaboration. Those involved in the network are often dining and commercial facilities pre-existing or caused to be born within a project for the hospitality widespread, in order to diversify the proposal and to make the life of the village more animated or charming.

It also provides tourists a unique experience of living in an old town or a village citizen.

Thus, this paper is divided in two parts. The first part 
propones a survey of the most recent contributions on:

- the competitiveness and attractiveness of territories and tourist destinations;

- the behavioral of tourist;

- the widespread hotel as a tool to promote the preservation of local culture and specificities of the small areas, the tourism development and leisure and business tourists satisfaction.

In the second part, the results of case study "Hotel Chateau Le Cagnard" are presented and commented on, highlighting the main classes of critical success factors and their features.

\section{Theoretical Background}

\subsection{Attractiveness and Competitiveness of Tourist Destination and Local Territory}

Is established that the attractiveness has become the target of recent urban policies. In fact, the constant appeals to events, be they even simple events or events lasting more days, or real places built for the occasion and adaptable to multiple uses, all linked to recreational activities, are a proof. [9].

The concept of competitiveness, initially referred only to businesses, has seen extend its meaning also to the territories even if this application is more complex. A territory can be defined competitive when it is able to compete in the market by ensuring, at the same time, an environmental, economic, social and cultural sustainability, based on inter-territorial network [10], [11], [12], [13], [14], [15], [16].

The competitiveness of a territory is the result of a virtuous circle in which three elements influence each other: territory, economic actors and resources. The territory makes available to economic actors a several factors and resources, tangible and intangible, essential to the achieve of competitive advantage. Economic actors move a substantial portion of the value created for the benefit of their territory, in this way they promote the progressive strengthening of its attractiveness and support its local development.

The competitive strategy of a territory is the acquisition of useful resources to ensure that the territory will become the context better than others to carry out economic activities more functional for its sustainable development.

The word "competitiveness", linked to a geographical area, is a concept widening used but its meaning is still unclear.

Among the most widely accepted definition of competitiveness, the OECD in 1992 offer the better one: "Competitiveness is the degree to which a nation can, in free and fair market conditions, produce goods and services that meet international competition, maintaining and expanding the real incomes of its people over the long term".

Competitiveness delves into the concept attractiveness in base on two perspectives. On the one hand the territories come into competition not only for economic gains, but also to attract flows through the quality of their physical structure and the enhancing of their image.

On the other hand, the concept of competitiveness is bound to attract enterprises which enrich and enhance their territory.
Caroli [17] identifies four determinants of territorial attractiveness: (1) physical characteristics, which include the topography, climatic and geographic conditions; (2) material capital, which includes infrastructures, the supply of means of production, the local production; (3) intangible capital, relations and trust shared, manufacturing expertise spread, vocation and image consolidated; (4) policies regarding the regulatory framework and control, management of public goods and services and the management of the factors of the public nature of the material and immaterial capital.

The territory can thus become a bulwark place to defend the specific production, the traditions, the culture of the place.

Today, it may be noted, in this regard, a growing sensitivity to the preservation of the "local", meaning the combination of supply harmonic that a territory can offer in terms of synthesis of its products, not only tangible but also intangible.

The concept of territory, therefore, is not considered in reality if not as a unitary and indivisible.

It is possible to look to the territory under three different meanings [18], which are actually present together and whole-people: (1) the territory as a destination, (2) the territory as a setting and (3) the territory as a network.

In the widespread hotel field the first and second concepts are very important.

The territory as a destination refers to the field of tourism.

The territory becomes a tourist product intended as a combination of elements to create a unique experience for the user, from the town, to the business set up in the area. Thus, from the point of view of the Destination Management, the offer that is proposed to the public includes the special features of a certain area, the activities and initiatives working on it. In short, the destination is not so much a place, but a set of activities and factors of attraction located in a defined space (location, site, area) that are able to propose an extensive and integrated proposal, that represent a specific and distinctive system of tourist hospitality that values the resources and local culture [19]

The concept of territory as a setting refers to a territory as environment, background, place of action on which it is established the culture of a people. In fact, the characteristics that affect the local identity and uniqueness become progressively of the key factors on which the development strategies of the territory are based to create differentiation and thus gain a competitive advantage [18].

This is how the area is open to the frontier of tourism oriented to the discovery, or rediscovery, of certain geographical areas.

So the offer must be organized as a real life experience in the area and not limited to an aggregate of resources; this logic experiential [20] is only possible due to the attitude of the territory to tell its tales, to drive interpretation, to give the tourist a unique and unforgettable memories, personal, non-replicable in other places.

The human element is the key for potential enhancement of an area [18] 


\subsection{Tourist Behavioral}

The tourism demand is experiencing in these recent years, a particular evolution process, which causes the increase of the degree of variety (always more marked segmentation processes) and variability in time and in space.

The enterprises and tourism system, in fact, should guide their strategic and marketing choices to the differentiated and personalized solutions for the tourists, respecting the criteria of economy and efficiency of management decisions. To supply experiences seems to be a way for makers to survive in the ever more competitive future [8].

Behind every act of buying lies a complex system of social and individual decisions and influences. Their understanding is a prerequisite both for a correct interpretation of tourist market both for a more effective selection of the levers of appropriate marketing mix for characteristics of the target segments.

This is due to the growing complexity related both for tourism demand, with the continuous emergence of new ways of enjoying of the tourist product and of new consumer segments, both for the competitive scenario characterized by the aggressive competition of new tourist destinations highly differentiated and highly competitive in terms of price/value.

These features are due to the complexity of the tourist product, which includes an extremely wide range of heterogeneous resources, activities and services, the existence of a time gap between the time of purchase and the time of consumption, and "experiential" nature of the process of exploitation, which is characterized by the high consumer involvement and includes sensory, affective and emotional perspectives.

\subsection{The Widespread Hotel}

The widespread hotel is a model of hotel designed to provide an experience of authentic life in a rural village.

The features of the model are developed by Dall'Ara [21], [22]. The widespread hotel as such indicates "a special type of hotel designed to provide guests with a unique experience of life in the historic center of a town or a village. This offers guests all the amenities of a traditional hotel that is hospitality, service, common areas and restaurants, although the rooms are spread in the town center, in an approximate radius of 200 meters from the central location of principal hotel in which they are located reception, common areas and restaurant. The rooms and/or apartments are located within existing buildings, recovered in respect of local tradition or designed so as to create the feeling of being in the host resident" [23]. It is an integral part of the sector of Hospitality Widespread, along with the country-hotel, the Diffuse Residence or Borgo Hotel which is united by nature "horizontal" proposal and the type of context, more often rural, in which it operates.

Widespread hotel has proven capable of holding the depopulation of villages. The same, however, requires the presence of support services targeted by the territorial organizations, interested in encouraging the emergence of these proposals in the areas of competence. This support was formalized in an ad-hoc intervention model for the development of widespread hotel [24], [25].

The models of hospitality and intervention have been recognized as innovative by the United Nations and the European network of business incubators (EBN) through the first prize awarded to the CEO for the international competition "Helping to Grow New Talents" held in 2008 in Budapest.

However, the widespread hotel model presents some obstacles difficult to overcome. Among them, the deviation between the large number of registered projects and the number of those actually operating in the area seems to indicate the presence of problems in the design and implementation steps of the proposals. From a regulatory point of view, significant differences emerge between the range of minimum quality requirements necessary to configure a widespread hotel based on the national model, and those recognized by some regional normative, more elastic and therefore more ambiguous [26].

A widespread hotel develops in with, not height and is therefore superimposed on the geography of the village. In this context, a line of research has addressed the issue of the acquisition and development of resource type urbanarchitectural, important for the process of value creation for the guest and thus can play a decisive role in the generation of income necessary to the support of accommodation widespread hospitality. It is an example of enterprise resource for widespread hotel the urban architecture or the skyline of the village.

\section{A New Accommodation Model for the Business Tourist: The Widespread Hotel}

\subsection{The Business Tourism in the French Riviera and the Cannes MIPIM Fair}

The French Riviera, originally only known as an holiday destination, has gradually become one of the major centers of international business tourism. Since 1950, with the construction of the Nice Exhibition Centre, the major hotels have equipped themselves and then created the dedicated structures. In 1978, Monaco (Monte-Carlo) inaugurated the auditorium and in 1982 in the convention center of Cannes replaced the former Palais des Festivals, in 1984 Nice inaugurated its Acropolis complex, completely renovated in 2011. Monaco opened the Grimaldi Forum in 2000 and his new palace Antibes in 2013.

At the same time, specialized agencies have supported the logistics of events. The palaces of Nice, Cannes and Monaco have auditoriums of more than 1,800 seats, there are nearly 500 hotels meeting rooms over 30 "event venues".

According to the French Riviera Tourism Observatory overall, in 2013 tourism flows generated by business purposes exceeded 2.000 .000 annually distributed in: $46 \%$ 
meetings or business appointments (down in recent years), $31 \%$ for conferences, seminars, symposia (recovery since 2010 after a decline since 2005), 10\% for fairs, expos (up from 98 when they represented only $0.4 \%$ and a peak of $16.9 \%$ in 2007 , up from 2012-13), $3 \%$ studies, training, training. Only $0.5 \%$ of visitors for business indicate "incentive" as a reason for living, but the "other professionals "increased sharply $(9.5 \%)$.

One of this important event is MIPIM [27] the world's leading property market that brings together the most influential players from all international property sectors (office, residential, retail, healthcare, sport, logistics and industrial, offering unrivalled access to the greatest number of development projects and sources of capital worldwide).

The event is held annually in Cannes. Last year, during the 4 days of exhibition, participants were 21000 coming from 93 different countries [28].

In the following part of the paper will be presented the results of a survey carried out on a sample of a delegation that took part to this event in March 2014.

\subsection{Case Study: Hotel Chateau Le Cagnard}

Built in the 13th century, Le Cagnard [29] is a stone dwelling integrated in the city wall of the medieval village of Haut-de-Cagnes. Its history is closely tied to that of the Château Grimaldi, which dates back to the 14th century.

The propriety has had different owners. In 2011, it was sold and proprietors decided to focus on hospitality and to develop an hotel according to the "widespread hotel" standards. So after undergoing a complete renovation (included the frescoes and antique furniture restoration), the hotel started focusing on both leisure and business segment.

A brief analysis of the main characteristics will follow:

Location:

The Hotel is located in Haut-de-Cagnes. It is a small hilltop village in the centre of the French Riviera and has successfully preserved its medieval character. The village is built on a top of hill and surrounds the Château Grimaldi, which is now a museum. The view of Cagnes-sur-Mer envisages both the sea and the rising hills of the backcountry. This village has been considered a privileged meeting point for artists, which led to its being named the "Montmartre of the French Riviera"

Accessibility:

The hotel is ideally connected and located in particular:

- by car: it provides quick access to the A8 highway (French Riviera Motorway);

- by train : the Cagnes-sur-Mer SNCF train station is close to the hotel;

- by bus: the central bus station, located in downtown Cagnes-sur-Mer connects with all the main cities along the French Riviera with regular service;

- by plane: the hotel is only 10 minutes (by car) far from the Nice French Riviera International Airport (connected as well with Monaco helicopter airport);

- there is a free shuttle service available for moving from the City of Cagnes-sur-Mer to the village of Haut-de-Cagnes which is useful for connecting the city with the parking placed at the edge of the village.

From the village of Haute-de-Cagne is easy to reach business and leisure destination like:

- Cannes (Congress Centre): 35 minutes

- Monaco (Principality): 45 minutes

- Ventimiglia (Italy): 55 minutes

- Saint-Tropez: $1 \mathrm{~h}$ and 15 minutes

Rooms:

The hotel has 28 rooms of which:

- 18 single and double room;

- 10 junior suites;

- 3 suites;

Every rooms offers air conditioning and free wi-fi.

Restaurant:

The restaurant offers Provencal cuisine with local and seasonal products.

It has specific formula for particular situations like Christmas a New Years' Eve.

It also organizes corporate Christmas Dinner.

Services:

The hotel provides high-level services for both business and leisure customers like:

- babysitting;

- cultural holidays: French classes, painting and drawing courses in the village and surrounding -area, perfume making, culinary courses, wine tasting;

- desk services: photocopies, fax, scanning, postal services, translations, etc.

- free Wi-Fi throughout the hotel;

- health, well-being and relaxation: massage, hairdresser, manicure and pedicure, nutritional advice, personal trainer, personal shopping assistant (which can be exclusively provided in the rooms)

- public transportation information: bus, train or boat;

- reservations: limousine, taxi, car or helicopter rentals, private excursions, local attractions and events, etc.

Services for business meeting:

The hotel facilities can be used as well to organize business meetings. Three rooms are available for seminars, conferences, assemblies and meetings.

For these occasions daily packages are offered, half-day with lunch and/or dinner as well as accommodation in single and or double rooms within the hotel.

The restaurant can prepare business meals, buffets or snacks during the meetings. Furthermore discretion and quietness is guaranteed by complimentary lounge (apart the main room) that can accommodate 2-15 guests.

All the meeting rooms are equipped with $\mathrm{Wi}-\mathrm{Fi}$, screen, video projector, flip chart. On request is always possible to get camcorder and sound equipment

In particular:

- -Piano Lounge can accommodate (depending on the configuration) from 10 to 25 businessmen

- -Suite Picasso (15 to 30 guests)

- -Guard Room (12 to 40 guests)

The main features will be summarized in the following table 1 . 
Table 1. Main Features of the hotel Le Cagnard.

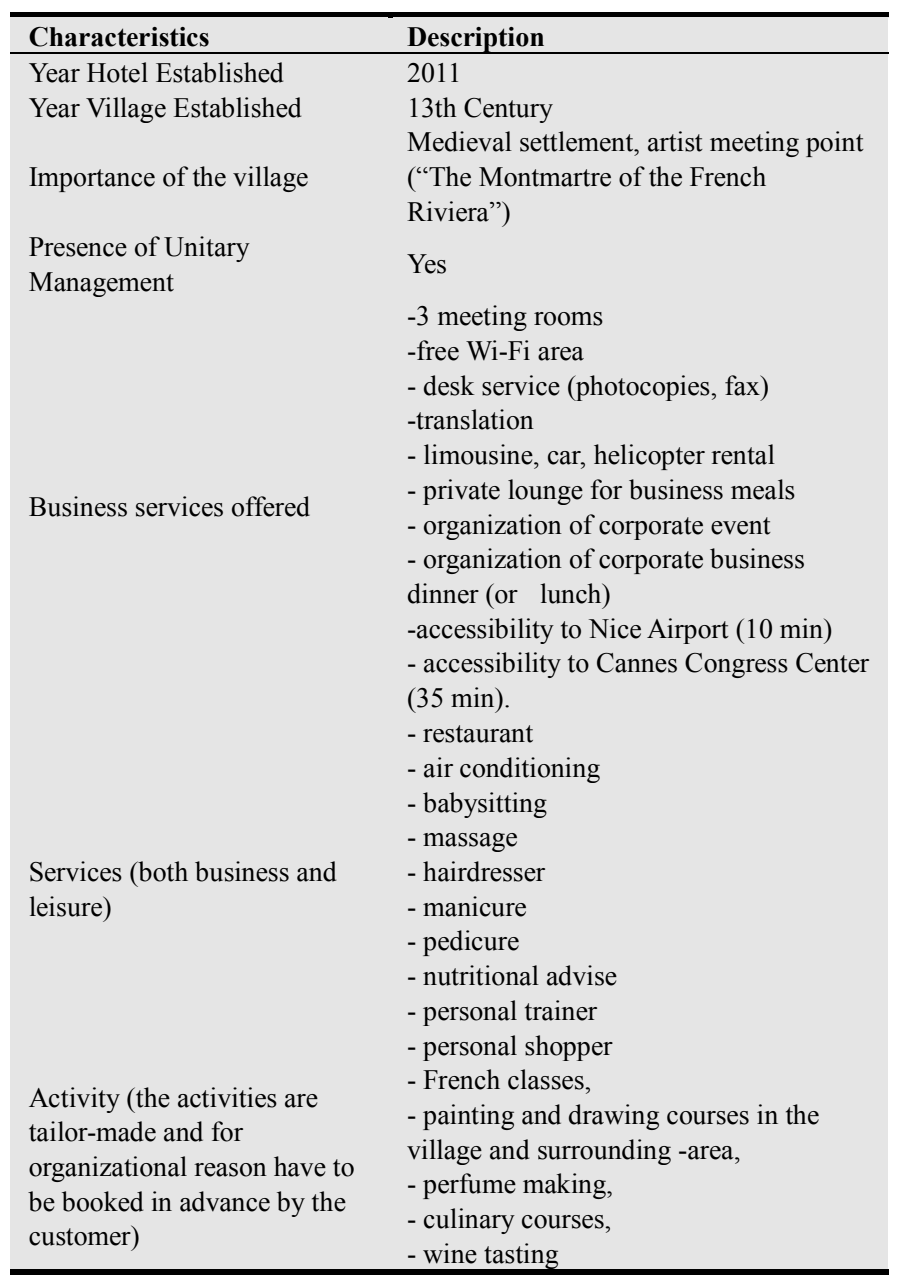

Source: our elaboration on primary data

\section{Discussion and Results}

In relation to the literature review the following research question has been identified:

"Can the hotel developed according to the "widespread hotel" model meet and satisfy the needs of the business tourist?"

To answer to this question it has been carried out a survey (based on both quantitative and qualitative data) on a sample of 48 businessmen that can be considered representative because:

- they are all top managers of Italian associations and organization,

- their professional profile (businessmen, manager, entrepreneur) has allowed them to travel extensively

- in the role of event organizers must sometimes choose the location to host their guests.

As shown in table 3 , the questionnaire is divided into three main parts:

- in the first part the respondents were asked to rate the hotel (on a scale from 1 to 10) and to tell the main points of strength of the hotel

- the second part is more focalized on the relevance of the choice of the hotel in relation to the business trip and on the analysis of the main reasons.

- in the third part it has been asked to the panel whether the "widespread hotel" could be successfully adopted in the Piedmont Region (Italian region from whom the majority of the businessman came from).

In particular questions $2,4,6,8$ were open ended questions, instead questions 1,3,5,7 were close-ended (most of them were single choice answers, only the question 2 was multiple choice).

Table 2. The questionnaire.

\begin{tabular}{ll}
\hline Nr. & Question \\
\hline 1 & $\begin{array}{l}\text { How do you rate from } 1 \text { to } 10 \text { the hotel in which you stayed during } \\
\text { your last business trip to Cannes? }\end{array}$ \\
2 & $\begin{array}{l}\text { Can you tell us the } 3 \text { points of strength of the hotel? } \\
\text { Do you think that the choice of the hotel was relevant to enjoy the } \\
\text { business event that you have attended? }\end{array}$ \\
5 & $\begin{array}{l}\text { Can you tell us the main reasons? } \\
\text { in the Piedmont region with the same success? }\end{array}$ \\
6 & $\begin{array}{l}\text { In which area? } \\
\text { Do you think the success of the model needs some particular } \\
\text { conditions? }\end{array}$ \\
\hline
\end{tabular}

Source: our elaboration on primary data

The main results of the survey are shown below.

In the first question, about the overall evaluation of the structure "Le Cagnard", the respondent had to express on a scale from 1 to 10 (where 1 stands for very bad and 10 stands for excellent).

The average value attributed was of 9.24 . The standard deviation of 1.02 shows that the variability from the mean value is not so high.

Table 3. How do you rate from 1 to 10 the hotel in which you stayed during your last business trip to Cannes?

\begin{tabular}{llll}
\hline Mean & St.Dev & Min & Max \\
\hline 9,24 & 1,02 & 6 & 10 \\
\hline
\end{tabular}

Source: our elaboration on primary data

Subsequently, each respondent was asked to list the main strengths (maximum 3 items) of the facility where he had stayed.

The responses indicate that the item most significant for the sample were:

- the proximity to the convention center;

- the quality of services offered within the structure (see table 1)

- the excellence of the landscape (and the experiential aspect related to the medieval village). The presence of this element was assumed given the historic-cultural context within the structures operate, which represent the starting point for the creation of natural value [29]

Less relevant appear to be the quality of the restaurant and the high standard of the rooms (aspect that can be explained by the fact that the sample, consisting of experienced business 
traveler, tends to take for granted these elements).

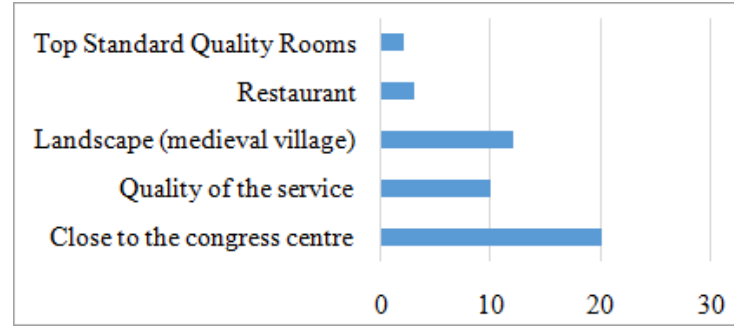

Source: our elaboration on primary data

Figure 1. Can you tell us the 3 points of strength of the hotel?

In question 3 was asked whether the choice of the specific structure has been considered relevant in order to enjoy the event in the best way. As a result $98 \%$ of the sample states that the choice was important and allowed them to enjoy the exhibition at the best.

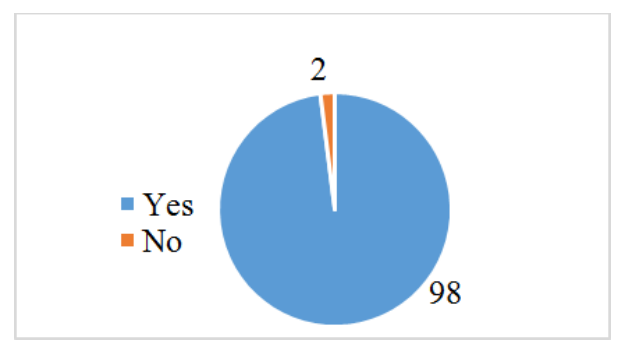

Source: our elaboration on primary data

Figure 2. Do you think that the choice of the hotel was relevant to enjoy the business event that you have attended.

The reasons (figure 3) have been given in detail in the answer to question 3. The most significant was that the "widespread hotel" offers at the meantime comfort and quick access to the cities of Nice and Cannes

Other answers were that:

- It facilitates, through the structure and business services (in particular the three meeting rooms) the activities of the team (such as teambuilding)

- The intimate atmosphere allowed the businessmen to relax at the end of the day's work.

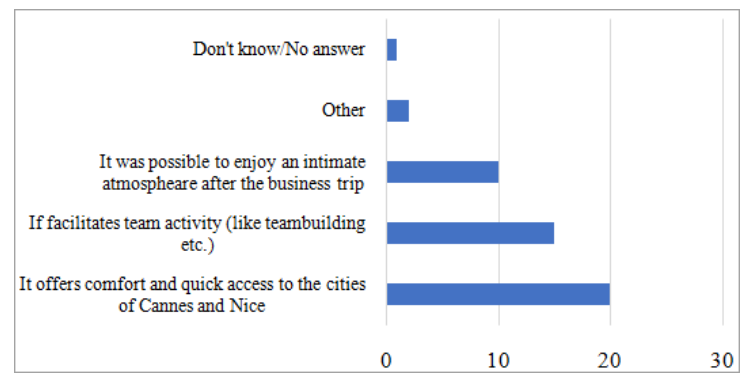

Source: our elaboration on primary data

Figure 3. Can you tell us the main reasons?

It has been finally asked the sample if in their opinion the "widespread hotel" model could also be adopted in the
Piedmont Region with the same success. $95 \%$ of them answered positively.

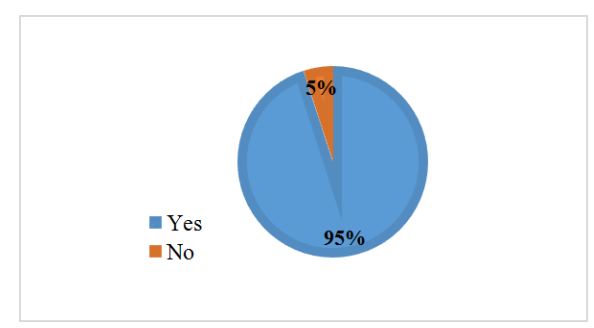

Source: our elaboration on primary data

Figure 4. Do you think that the "widespread hotel" model could be adopted in the Piedmont region with the same success?

About the area in which the model could be more successful, it prevails a clear majority for the mountain area, followed by the system from the lakes and hills.

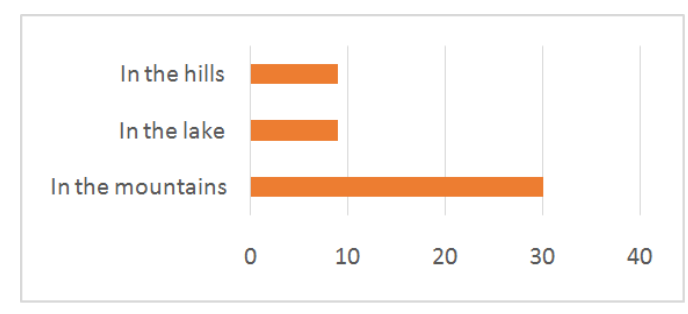

Source: our elaboration on primary data

Figure 5. In which area?

It was finally asked to respondents if the success of the application of the model were due to special reasons. $93 \%$ of the sample responded affirmatively.

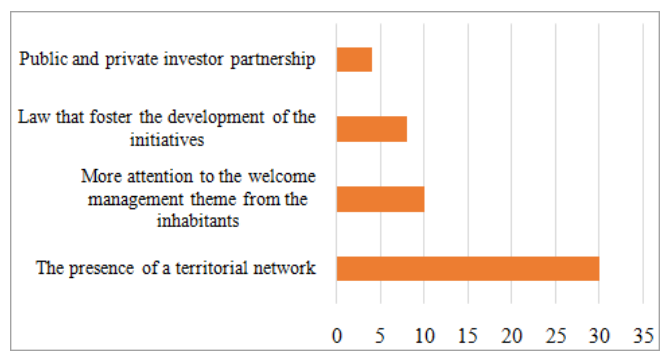

Source: our elaboration on primary data

Figure 6. Do you think the success of the model needs some particular conditions?

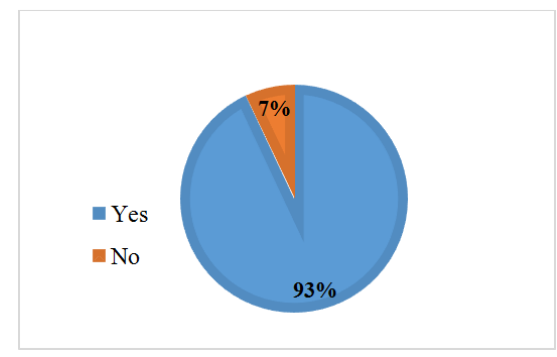

Source: our elaboration on primary data

Figure 7. If you answered "yes" to question 7 can you tell the most important condition in your opinion? 
In particular, confirming the theories of Caroli [17] the main reasons considered were:

- the importance of the presence of a territorial network with whom the structure can establish relationships;

- the increased attention to the issues of welcome management for residents;

- the presence of laws that foster the development of these initiatives;

- the activation of positive synergies through the public-private partnership.

\section{Conclusions}

The "widespread hotel" can be an important player for the tourism market, while promoting at the same time sustainable economic development in the territory where it operates [31].

Critical success factors are made up by those variables that management can control, and those variables that management must consider as constraints to ensure the enterprise's survival. Following the theories of Orlandini [32].et al, only by operating in this way, can the enterprise be a generator of economic and social value.

The most important classes of critical success factors for the "widespread hotel" are:

- the characteristics of the environment;

- the characteristics related to the market or to the market segment;

- the strategies implemented by the economic actor.

Regarding the characteristics of the environment the most significant are:

- the territorial ties;

- the influence of the local community on the structure.

According to Pine and Gilmore observations [20], the analyzed data showed that the "widespread hotel", combining experiential aspects and elements of service excellence, might represent the optimal solution for the business tourist.

In order for this to happen, however, must be some basic determinants of territorial attractiveness which have been identified by Caroli [17] such as:

- the presence of a territorial network with whom the structure can activate relations;

- the sensitivity of the population to welcome management theme;

- a legislation that allows the development of these initiatives.

The model of the widespread hotel can be a solution to enhance the value of certain territories.

In fact, according to Giuseppe Provvisiero [34]: "I think that, if placed in the proper context, the "widespread hotel" can be an efficient model of hospitality based on the driver of sustainability and innovation".

However, the hotel does not have to remain isolated; otherwise, the limited complementary offer (of cultural events, sports, entertainment etc.) can cause a loss of appeal.

In this regard, Provvisiero[34], according to Ingallina [9]: "The first vital element is the presence of a range of infrastructure, facilities and tourist accommodation with whom the "widespread hotel" can activate synergies and virtuous processes.

The presence of a conference center and the easy accessibility to the city center are an important amplifier.

In this regard, the strength of the structure analyzed corresponds to its ability to interrelate with the eco-system generated by the congress tourism and activating synergies with it. The many personalized services for business (such as the presence of some meetings room, the possibility of having an interpreter or booking a shuttle or limousine to reach the location and venues) make it an optimal solution for this target, and an efficient opportunity for value creation for both the territory and its stakeholders.

\section{Acknowledgements}

Although this paper is based on a combined effort, Prof. Filippo Monge is to take credit for paragraphs 4 and 5; Daniele Cattaneo is to take credit for paragraph 3; while Angela Scilla for paragraphs 1 and 2 .

\section{References}

[1] R. Gemmiti and L. Salvati, "Turismo e competitività territoriale. Un contributo geografico-economico", XXXI Italian Conference of Regional Science, 20-22 september 2010

[2] D.B. Weaver, Sustainable Tourism, New York: Routledge 2006.

[3] R. Scheyvens and J.H. Momsen, "Tourism and Poverty Reduction: Issues for Small Island States," in. Tourism Geographies: An International Journal of Tourism Space, Place and Environment, vol 10 n.1, 2008, pp. 22-41.

[4] (Quein, Sansbury, Le Bruto, 1998)

[5] M. Mowforth and I. Munt, Tourism and Sustainability. Development, Globalisation and New Tourism in the Third World. London: Routledge, 2008.

[6] S.F. McCool, R.N. Moisey and N.P. Nickerson, "What Should Tourism Sustain? The Disconnect with Industry Perceptions of Useful Indicators" in Journal of Travel Research, vol 40 n.2, 2001, pp. 124-131.

[7] S. Tsaur, Y. Chiu, and C. Wang, "The visitors' behavioural consequences of experiential marketing,"in Journal of Travel \& Tourism Marketing, vol. 21 n. 1, 2007, pp. 47-64.

[8] E. Binkhorst and D.D. Teun, „Agenda for Co-Creation Tourism Experience Research," in Journal of Hospitality Marketing \& Management, vol. 18 n.2-3, 2009, pp. 311-327.

[9] P. Ingallina, "Nuovi scenari per l'attrattività delle città e dei territori. Dibattiti, progetti e strategie in contesti metropolitani mondiali”, FrancoAngeli,Milano, 2010.

[10] D.G. Pearce, "Competitive Destination Analysis in Southeast Asia," in Journal of Travel Research, vol. 36 n.1, 1997, pp. 16-24.

[11] S.S. Hassan, "Determinants of Market Competitiveness in an Environmentally Sustainable Tourism Industry," in Journal of Travel Research, vol. 38 n.3, 2000, pp. 239-245. 
[12] J.R.B. Ritchie and G.I. Crouch, "The Competitive Destination. A Sustainable Tourism Perspective", Wallingford, Cabi International, 2003.

[13] M.J. Enright and J. Newton, "Determinants of Tourism Destination Competitiveness in Asia Pacific: Comprehensiveness and Universality," in Journal of Travel Research, vol. 43 n.1, 2005, pp. 339-350.

[14] W.C. Hong, "Global Competitiveness Measurement for the Tourism Sector" in Current Issues in Tourism, vol. 12 n. 2, 2009, pp. 105-132.

[15] M. Franch, U. Martini and F. Buffa, "Profili hard-path e soft-path dei turisti 4L in Italia: risultati di un'indagine sui viaggiatori del Cts", Disa Working Paper, (2), 2010, pp.1-61.

[16] G. Tardivo, M. Viassone and A. Scilla, "How to become a benchmark sustainable tourist destination? A descriptive model," Business Systems Review, vol. 3 issue 2., 2014, pp. 207-230.

[17] M. Caroli, "Il marketing territoriale: idee ed esperienze nelle regioni italiane" Franco Angeli, Milano, 2010

[18] L. Gavinelli, "Territoio, networking e management come dimensioni di analisi per le decisioni degli ecomusei italiani”, Cedam, Padova, 2012.

[19] M. Rispoli and M. Tamma, "Risposte strategiche alla complessità: le forme di offerta dei prodotti alberghieri", Giappichelli, Torino, 1995.

[20] B. Pine and H. Gilmore, H., "L'economia delle esperienze. Oltre il servizio", Etas, Milano, 2000.

[21] G. Dall'Ara, "Realizzare un Albergo Diffuso: dai principi teorici alle esperienze concrete", in: L'albergo Diffuso come strumento innovativo per la valorizzazione del potenziale turistico, quaderni BICNotes, n. 4, dicembre 2007, Business Innovation Center - BIC del Lazio, Roma, 2007

[22] G. Dall'Ara, "Manuale dell'Albergo Diffuso, l'idea, la gestione, il marketing dell'ospitalità diffusa, Franco Angeli, Milano, 2010 .

[23] UNDP-EBN (2008), brochure: "Albergo Diffuso: Developing Tourism Through Innovation and Tradition', IDEASS Programme, Italy, Innovation for Development and South-South Cooperation: http://www.ideassonline.org/public/pdf/br_47_01.pdf.
[24] G. Dichter, L'approccio metodologico BIC Lazio alla creazione di alberghi diffusi", in L'Albergo Diffuso come strumento innovativo per la valorizzazione del potenziale turistico, quaderni BICNotes, n. 4, dicembre 2007, BIC Lazio, Roma, pp. $74-81$

[25] M. Droli, "Tuscia romana, area Monti Ausoni: individuazione delle località più adatte ai fini della creazione di un Albergo Diffuso", in L'Albergo Diffuso come strumento innovativo per la valorizzazione del potenziale turistico, quaderni BICNotes, $n$. 4, dicembre 2007, BIC Lazio, Roma, pp. 49-72.

[26] M. Droli and G. Dall'Ara, "Ripartire dalla Bellezza. Gestione e marketing delle Opportunità d'Innovazione nell'Albergo Diffuso, nei Centri Storici e nelle Aree Rurali”, CLEUP, Padova, 2012.

[27] www.mipim.com

[28] www.cotedazur-touriscope.com/pdf/fiches/8/normal.pdf

[29] ww.lecagnard.com

[30] G.M. Golinelli and M. Gatti, "L'impresa sistema vitale. Il governo dei rapporti intersistemici" in Symphonya. Emerging Issues in Management, ISTEI, Milano, University of Milan-Bicocca, 2002, pp. 53-81.

[31] G.Tardivo, G. Quaglia, "La creazione di valore, Vol I, La creazione di valore per l'impresa", Franco Angeli, Milano, 2013, p. 72.

[32] . Orlandini, C.Vallone, A. De Toni, R. Cecchetti, (2012). Total quality research of tourism services. Special case: "Spread hotel". In: 15th International Conference on Quality Service Sciences, Rishon Lezion, Israel, 3-5 September 2012, pp. 4-5.

[33] G. Dall'Ara, Manuale dell'Albergo diffuso; l'idea, la gestione, il marketing dell'ospitalità, Franco Angeli, Milano, 2010, p. 15

[34] President of ANCE Piemonte and Valle d'Aosta and vice president of Confindustria Piemonte (insights in F. Monge, G. Provvisiero, Il settore delle costruzioni in Piemonte e Valle d'Aosta, mercati, dinamiche, strutture, Egea, Milano, 2014). 